\title{
Genes de enterotoxinas e perfil antimicrobiano de Escherichia coli isoladas de suínos hígidos no Distrito Federal
}

\author{
[Enterotoxin genes and antimicrobial profile of Escherichia coli isolated from healthy \\ swines in Distrito Federal, Brazil]
}

\section{V.O. Drummond, S. Perecmanis}

Laboratório de Microbiologia Médica Veterinária - FAV - Universidade de Brasília (UnB) - Brasília, DF

\section{RESUMO}

Um total de 127 cepas de Escherichia coli foi isolado de suínos no Distrito Federal, testado para a presença de genes de enterotoxinas (STa, LT-I, LT-II, Stx ${ }_{1}$ e $\mathrm{Stx}_{2}$ ) e para resistência antimicrobiana. Das cepas isoladas, oito $(6,3 \%)$ possuíam genes para enterotoxinas, sendo quatro $(3,2 \%)$ positivas somente para LT-I, três $(2,4 \%)$ somente para STa e uma $(0,8 \%)$ positiva para STa e LT-I. Nenhuma das cepas isoladas apresentou genes para LT-II, Stx 1 ou $\mathrm{Stx}_{2}$. Quanto ao perfil de resistência antimicrobiano, os antibióticos com maiores porcentagens de resistência foram lincomicina (100\%), sulfonamidas $(74,8 \%)$ e tetraciclina $(70,1 \%)$, enquanto os maiores índices de sensibilidade foram observados na norfloxacina $(82,7 \%)$, gentamicina $(75,6 \%)$ e sulfametoxazol + trimetoprim $(63 \%)$. Esses resultados demonstraram a presença de genes de enterotoxinas e altas taxas de resistência antimicrobiana em $E$. coli isoladas de suínos hígidos no DF.

Palavras-chave: Escherichia coli, suíno, enterotoxinas, resistência antimicrobiana

\begin{abstract}
A total of 127 strains of Escherichia coli were isolated from swines in Distrito Federal, Brazil, tested for enterotoxin genes (STa, LT-I, LT-II, Stx 1 and Stx $x_{2}$ ) and for antimicrobial resistance. Eight strains (6.3\%) had enterotoxin genes, of which four (3.2\%) were positive only for LT-I, three (2.4\%) positive only for STa and one $(0.8 \%)$ positive for STa and LT-I. There were no positive strains for LT-II, Stx $x_{1}$ or Stx $x_{2}$. When antimicrobial resistance was analyzed, the most resistant antibiotics were Lincomycin (100\%), Sulfonamide (74.8\%) and Tetracycline (70.1\%), and the most sensitive antimicrobials were Norfloxacin (82.7\%), Gentamicin (75.6\%) and Sulfamethoxazole + Trimethoprim (63\%). These results demonstrated the presence of enterotoxin genes and high numbers of antimicrobial resistance of E. coli strains isolated from healthy swines in Distrito Federal.
\end{abstract}

Keywords: Escherichia coli, swine, enterotoxins, antimicrobial resistance

\section{INTRODUÇÃO}

Doenças entéricas de etiologia bacteriana, principalmente por Escherichia coli, têm crescente importância na suinocultura, com grande impacto na indústria de produtos de origem suína em todo o mundo (Menin et al., 2008). Essa bactéria foi considerada, por muito tempo, um organismo não patogênico do trato entérico, mas estabeleceu-se nas últimas décadas como importante agente de doenças entéricas (Kaper et $a l ., 2004)$, sendo que as $E$. coli enterotoxigênicas
(ETEC) produtoras de toxinas termolábil (LT) e termoestável (ST) estão entre as principais causadoras de diarreia nos suínos (Zhang e Francis, 2010).

A resistência antimicrobiana é um problema sério tanto na medicina veterinária quanto na humana, e o estudo do perfil de resistência previne o uso de antibióticos de amplo espectro no tratamento dos animais, o que pode evitar o aparecimento de bactérias resistentes encontradas nos animais e no ambiente em que vivem (Macêdo et al., 2007).

Recebido em 9 de março de 2012

Aceito em 11 de março de 2013

E-mail: vodrummond@yahoo.com.br 
No Brasil são escassos os estudos que analisam a frequência de fatores de virulência de $E$. coli isoladas de suínos hígidos (Martins et al., 2010; Carlos et al., 2011). Esses dados têm grande importância quando se pretende identificar e solucionar problemas sanitários e implantar, nas unidades de produção suína, programas de biosseguridade (Menin et al., 2008).

O objetivo deste estudo foi verificar a existência de genes codificadores de enterotoxinas termolábil-I (LT-I), termolábil-II (LT-II), termoestável a (STa) e verotoxinas $1\left(\mathrm{Stx}_{1}\right)$ e 2 $\left(\mathrm{Stx}_{2}\right)$ em E. coli isoladas de fezes de suínos hígidos em suinoculturas no Distrito Federal e avaliar o perfil fenotípico de resistência antibacteriana.

\section{MATERIAL E MÉTODOS}

Amostras fecais de 109 suínos de raças distintas, de ambos os sexos e com idades variando de 21 dias a um ano, foram obtidas com swab diretamente da ampola retal, e processadas no Laboratório de Microbiologia Médica Veterinária da Universidade de Brasília (UnB). Os animais foram escolhidos aleatoriamente nas propriedades criadoras, em seis diferentes Regiões Administrativas do Distrito Federal (Ceilândia, Gama, Paranoá, Planaltina, Recanto das Emas e São Sebastião).

As colônias de E. coli foram isoladas em ágar MacConkey (MERCK, Jacarepaguá, RJ), sendo que algumas amostras apresentavam dois tipos de colônia (mucoide e não mucoide), o que resultou em 127 cepas estudadas. Foram também cultivadas em caldo BHI (MERCK, Jacarepaguá, RJ) para extração de DNA, segundo protocolo citado por Blanco et al. (1997).

As reações de PCR foram realizadas em volume final de $25 \mu \mathrm{L}$, contendo $5 \mu \mathrm{L}$ do DNA extraído; $2,5 \mu \mathrm{L}$ de solução tampão 10x (PHONEUTRIA, Belo Horizonte, MG); $0,75 \mu \mathrm{L}$ de $\mathrm{MgCl}_{2} 50 \mathrm{mM}$ (PHONEUTRIA, Belo Horizonte, MG); 1,25 $\mu \mathrm{L}$ de dNTP 10mM (INVITROGEN, São Paulo, $\mathrm{SP}) ; 0,5 \mu \mathrm{L}$ de Taq DNA polimerase $5 \mathrm{U} / \mu \mathrm{L}$ (PHONEUTRIA, Belo Horizonte, MG) e $0,5 \mu \mathrm{L}$ de cada primer (forward e reverse) específico para enterotoxina $(10 \mathrm{pmol} / \mu \mathrm{L})$. A sequência de nucleotídeos, o tamanho dos amplicons e a temperatura de anelamento (T.A.) estão descritos na Tab. 1.

Tabela 1. Oligonucleotídeos utilizados neste trabalho e o tamanho dos amplicons

\begin{tabular}{cccc}
\hline Toxina & Sequência $\left(5^{\prime}-3^{\prime}\right)$ & Amplicon $(\mathrm{bp})$ & T.A. \\
\hline STa & 5- TCCGTGAAACAACATGACGG -3 & 244 & \multirow{2}{*}{$59^{\circ} \mathrm{C}$} \\
& 5- ATAACATCCAGCACAGGCAG -3 & & \\
LT-I & 5- TATCCTCTCTATATGCACAG -3 & 480 & $48^{\circ} \mathrm{C}$ \\
& 5- CTGTAGTGGAAGCTGTTATA -3 & & \\
LT-II & 5- AGATATAATGATGGATATGTATC -3 & 300 & $48^{\circ} \mathrm{C}$ \\
& 5- TAACCCTCGAAATAAATCTC -3 & & \\
Stx $_{1}$ & 5- AGGTTGCAGCTCTCTTTCAATA -3 & 364 & $57^{\circ} \mathrm{C}$ \\
& 5- TGCAAACAAATTATCCCCTGAG -3 & & \\
Stx $_{2}$ & 5- GGGCAGTTATTTTGCTGTGGA -3 & 386 & $59^{\circ} \mathrm{C}$ \\
& 5- GTATCTGCCTGAAGCGTAA -3
\end{tabular}

Fonte: Salvadori et al., 2003.

As colônias foram inoculadas em caldo e ágar Müeller-Hinton (MERCK, Jacarepaguá, RJ) para realização do antibiograma segundo o método de Kirby-Bauer modificado - e testadas para antibióticos comumente utilizados na suinocultura (Menin et al., 2008; Silva et al., 2008; Costa et al., 2006): amicacina (AMI), ampicilina (AMP), cefalexina (CFE), cloranfenicol (CLO), doxiciclina (DOX), enrofloxacina (ENO), estreptomicina (EST), gentamicina (GEN), lincomicina (LIN), neomicina (NEO), norfloxacina (NOR), sulfametoxazol + trimetoprim (SUT), sulfonamidas (SUL) e tetraciclina (TET).

Este trabalho foi avaliado pelo Comitê de Ética no Uso Animal (Ceua) da Universidade de Brasília, tendo sido aprovado (UnBDoc 59523/2009). 


\section{RESULTADOS E DISCUSSÃO}

Do total de 127 cepas, oito (6,3\%) possuíam genes para enterotoxinas, sendo que três foram positivas somente para STa $(2,4 \%)$, quatro somente para LT-I $(3,2 \%)$, e uma possuía genes para essas duas toxinas (Fig. 1). Nenhuma cepa foi positiva para as demais toxinas testadas (LTII, Stx $_{1}$ e Stx 2 ).

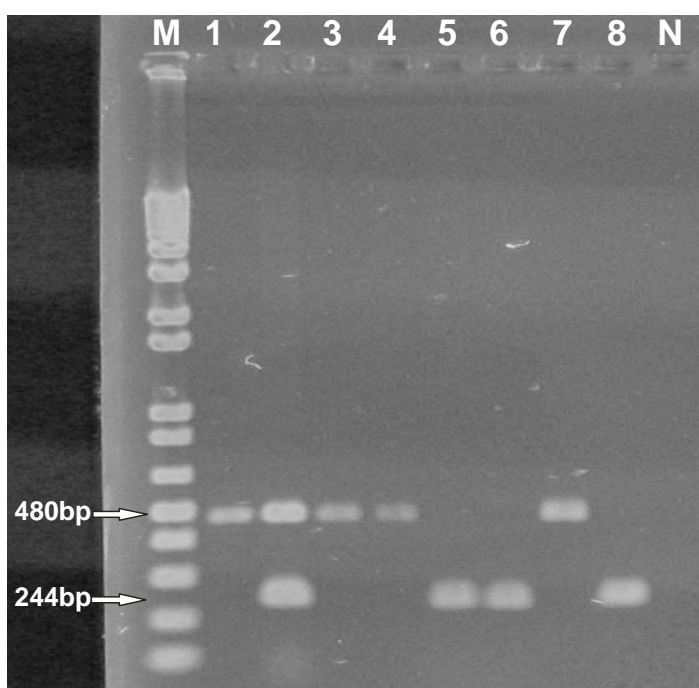

Figura 1. Eletroforese em gel de agarose dos resultados da amplificação dos genes. $\mathrm{M}$ (marcador de peso molecular); 1 (EC027); 2 (EC029A); 3 (EC030); 4 (EC040); 5 (EC051A); 6 (EC076); 7 (EC099); 8 (EC108); N (controle negativo); bp (pares de bases).

Os suínos não são considerados a principal fonte de E. coli produtoras de toxinas de Shiga (STEC) pelo fato de terem uma prevalência normalmente muito baixa, enquanto as E. coli produtoras de LT e ST normalmente são isoladas de suínos com diarreia pós-desmame (Martins et al., 2010). Genes codificadores de toxinas são comumente isolados em casos de suínos com diarreia (Menin et al., 2008), mas a identificação de genes de toxinas em suínos hígidos não é tão frequente (Kaper et al., 2004).

Schierack et al. (2006), em trabalho com suínos hígidos, encontraram $8,5 \%$ de cepas contendo apenas gene para STa e 3,9\% somente para LT-I, valores próximos aos encontrados neste estudo. Valores semelhantes também foram encontrados por Martins et al. (2010), que estudaram a prevalência de $E$. coli com genes para enterotoxinas em suínos de abatedouros no Mato
Grosso e isolaram 1,35\% de cepas positivas para $\mathrm{Stx}_{2} ; 6,76 \%$ de cepas positivas para STa apenas; e 2,70\% com genes de STa e LT-I associadas. Estes números demonstram uma baixa - porém existente - presença de genes de enterotoxinas de cepas isoladas em animais hígidos.

Com o antibiograma, traçou-se um perfil de sensibilidade das E. coli. Cento e vinte e sete amostras foram resistentes a pelo menos um antibiótico; $92(72,44 \%)$ a pelo menos quatro antibióticos; e quatro $(3,2 \%)$ não apresentaram sensibilidade a nenhum dos antibióticos testados. Os antibióticos que tiveram maior porcentagem de E. coli sensíveis neste estudo foram a norfloxacina $(82,7 \%)$, gentamicina $(75,6 \%)$, e sulfametoxazol + trimetoprim (63\%), enquanto as mais resistentes foram lincomicina - com todas as cepas resistentes -, sulfonamidas $(74,8 \%)$ e tetraciclina $(70,1 \%)$. As porcentagens aos antibióticos podem ser vistas na Fig. 2.

Neste trabalho, verificou-se um alto índice de bactérias com multirresistência aos antimicrobianos testados, resultados condizentes com Hirsh e Zee (2003), que afirmam que cepas de E. coli usualmente são resistentes às sulfonamidas, tetraciclina, estreptomicina, ampicilina e kanamicina. Os resultados observados neste estudo também estão de acordo com os trabalhos de Silva et al. (2008) e Costa $e t$ al. (2006), os quais também identificaram cepas com altas taxas de resistência.

Considerando que a utilização do cloranfenicol para uso veterinário foi proibida desde a publicação da Instrução Normativa n ${ }^{\circ}$, de 27 de junho de 2003 (Brasil, 2003), a presença de $34,7 \%$ de cepas resistentes a esse antibiótico demonstra um dado interessante, principalmente porque a quase totalidade $(90,9 \%)$ dessas cepas resistentes foram isoladas de granjas comerciais. Isso talvez possa ser explicado pela manutenção por meio de cosseleção dos genes de resistência a esse antibiótico com outros genes de resistência e genes de virulência (Rosengren et al., 2009).

Observou-se também uma alta prevalência de cepas resistentes à lincomicina. Todas as cepas isoladas foram resistentes a esse antibiótico, o que demonstra ser um dado preocupante para a produção animal. Essa resistência pode estar relacionada à utilização em larga escala de lincomicina no tratamento e na profilaxia de 
diarreias e como facilitador de crescimento na suinocultura (Baccaro et al., 2002). Três cepas que apresentaram multirresistência foram isoladas de uma mesma propriedade - uma suinocultura industrial -, o que talvez possa ser justificado pelo costume da utilização, em larga escala de antimicrobianos na prevenção e no favorecimento de crescimento na suinocultura industrial quando comparada com a suinocultura de subsistência (Wang et al., 2010).

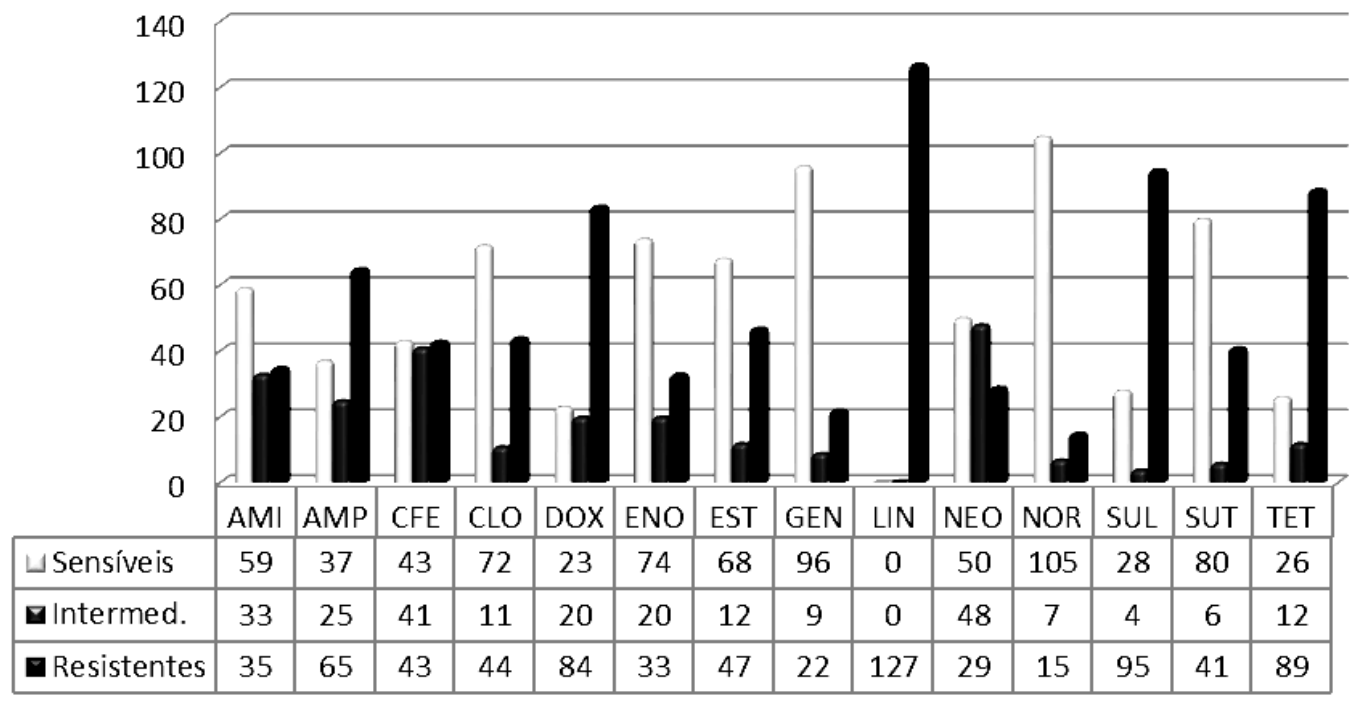

Figura 2. Perfil de resistência de E. coli isoladas.

\section{CONCLUSÕES}

Neste estudo, foram identificadas cepas de $E$. coli com genes codificadores de STa e LT-I em suínos hígidos, o que pode favorecer o aparecimento de diarreias nos animais e o risco de transmissão para o homem. A alta taxa de resistência a antibióticos encontrada neste estudo demonstra uma tendência mundial ao isolamento de bactérias multirresistentes, que pode ser devido à utilização indiscriminada de antibióticos na suinocultura.

\section{AGRADECIMENTOS}

Ao Professor Marcos Bryan Heinemann, da Escola de Veterinária da UFMG, por ter cedido as cepas-controle positivas.

\section{REFERÊNCIAS}

BACCARO, M.R.; MORENO, A.M.; CORRÊA, A. et al. Resistência antimicrobiana de amostras de Escherichia coli isoladas de fezes de leitões com diarreia. Arq. Inst. Biol., v.69, p.15-18, 2002.
BLANCO, M.; BLANCO, J.E.; BLANCO, J. et al. Distribution and characterization of faecal verotoxin-producing Escherichia coli isolated from healthy cattle. Vet. Microbiol., v.54, p.309319, 1997.

BRASIL. Ministério da Agricultura, Pecuária e Abastecimento, MAPA. Instrução Normativa $\mathrm{n}^{\circ}$ 9 de 27 de junho de 2003.

CARLOS, C.; ALEXANDRINO, F.; VIEIRA, M.A.M. et al. Prevalence of virulence factors in Escherichia coli isolated from healthy animals and water sources in Brazil. J. Water Health. v.9, p.138-142, 2011.

COSTA, M.M.; SILVA, M.S.; SPRICIGO, D.A. et al. Caracterização epidemiológica, molecular e perfil de resistência aos antimicrobianos de Escherichia coli isoladas de criatórios suínos do sul do Brasil. Pesq. Vet. Bras., v.26, p.5-8, 2006.

HIRSH, D.C.; ZEE, Y.C. Microbiologia Veterinária. 1.ed. Rio de Janeiro: Guanabara Koogan, 2003. 464p.

KAPER, J.B.; NATARO, J.P.; MOBLEY, H.L.T. Pathogenic Escherichia coli. Nature Reviews: Microbiology. v.2, p.123-140, 2004. 
MACÊDO, N.R.; MENEZES, C.P.L.; LAGE, A.P. et al. Detecção de cepas patogênicas pela PCR multiplex e avaliação da sensibilidade a antimicrobianos de Escherichia coli isoladas de leitões diarreicos. Arq. Bras. Med. Vet. Zootec. v.59, p.1117-1123, 2007.

MARTINS, R.P.; SILVA, M.C.; DUTRA, V. et al. Prevalence of enterotoxigenic end Shiga toxin-producing Escherichia coli in pigs slaughtered in Mato Grosso, Brazil. J. Infect. Dev. Ctries, v.5, p.123-126, 2010.

MENIN, A.; RECK, C.; SOUZA, D. et al. Agentes bacterianos enteropatogênicos em suínos de diferentes faixas etárias e perfil de resistência a antimicrobianos de cepas de Escherichia coli e Salmonella spp. Cienc. Rural, v.38, p.1687-1693, 2008 .

ROSENGREN, L.B.; WALDNER, C.L.; REIDSMITH, R.J. Associations between Antimicrobial Resistance Phenotypes, Antimicrobial Resistance Genes, and Virulence Genes of Fecal Escherichia coli Isolates from Healthy Grow-Finish Pigs. Appl. Environ. Microbiol., v.75, p.1373-1380, 2009.
SALVADORI, M.R.; VALADARES, G.F.; LEITE, D.S. et al. Virulence factors of Escherichia coli isolated from calves with diarrhea in Brazil. Braz. J. Microbiol., v.34, p.230-235, 2003.

SCHIERACK, P.; STEINRÜCK, H.; KLETA, S. et al. Virulence Factor Gene Profiles of Escherichia coli Isolates from Clinically Healthy Pigs. Appl. Environ. Microbiol., v.72, p.66806686, 2006.

SILVA, F.F.P.; SANTOS, M.A.A.; SCHMIDT, V. Resistência a antimicrobianos de Escherichia coli isolada de dejetos suínos em esterqueiras. Arq. Bras. Med. Vet. Zootec., v.60, p.762-765, 2008.

WANG, X.; JIANG, H.; LIAO, X. et al. Antimicrobial resistance, virulence genes, and phylogenetic background in Escherichia coli isolates from diseased pigs. FEMS Microbiol. Lett. v.306, p.15-21, 2010.

ZHANG, W.; FRANCIS, D.H. Genetic fusions of heat-labile toxoid (LT) and heat-stable toxin b (STb) of porcine enterotoxigenic Escherichia coli elicit protective anti-LT and anti-STb antibodies. Clin. Vaccine Immunol., v.17, p.1223-1231, 2010. 